\title{
A PRODUÇÃO DA “PARIS DOS TRÓPICOS” E OS MEGAEVENTOS NO RIO DE JANEIRO NO INÍCIO DO SÉCULO XX
}

Fabio Silveira Molina ${ }^{1}$

RESUMO - O tema central deste artigo foca o papel dos megaeventos na produção do espaço urbano do Rio de Janeiro no início do século XX. Nesse momento, a partir da realização de consideráveis transformações urbanas, buscava-se associar o Rio de Janeiro à imagem de "Paris dos Trópicos" e, ao mesmo tempo, a cidade sediou dois importantes megaeventos: a Exposição Nacional de 1908 e a Exposição Internacional de 1922. Esses megaeventos configuraram-se enquanto estratégias urbanas promovidas pelo Estado, e as modernizações territoriais decorrentes se mostraram altamente seletivas e excludentes, acentuando ainda mais a produção de espaços elitizados e a segregação sócio-espacial. Utilizados como pretexto à expansão urbana e à produção e conquista de solo urbano, os megaeventos analisados induziram redefinições dos usos do solo e de seu arranjo no espaço interno da cidade, mostrando-se relevantes na estruturação da cidade do Rio de Janeiro.

Palavras-chave: Megaeventos; geografia urbana; produção do espaço urbano; estruturação urbana; Exposição Nacional 1908; Exposição Internacional 1922.

ABSTRACT - The production of the "Paris of the Tropics" and mega-events in Rio de Janeiro in the EARLy twentieth CEntury. The central theme of this article is based on the role of mega-events in the production of Rio de Janeiro's urban space in the early twentieth century. At this time, through considerable urban transformations, the image of the city was associated with "Paris of the Tropics." At the same time, the city hosted two important mega-events: the 1908 National Exhibition and the 1922 International Exhibition. These mega-events were configured as urban strategies promoted by State, and the territorial modernizations arising from the mega-events were highly selective and exclusive, producing even more elite places and socio-spatial segregation. Used as a pretext to urban expansion, production and the conquest of urban lands, the mega-events analyzed induced

1 Doutor pelo Programa de Pós-Graduação em Geografia Humana da Universidade de São Paulo (USP), Faculdade de Filosofia, Letras e Ciência Humanas (FFLCH), Departamento de Geografia, 72042, Av. Prof. Lineu Prestes, 338 - Cidade Universitária, São Paulo, Brasil. E-mail: fmolina@usp.br 
redefinitions of land uses and their arrangement in the internal space of the city, demonstrating their relevance in the structuring of the city of Rio de Janeiro.

Keywords: Mega-events; urban geography; production of urban space; urban structuring; 1908 National Exhibition; 1922 International Exhibition.

RÉSUMÉ - LA Production dU “PARIS des Tropiques" et les MÉGA-ÉVÉnements À Rio DE JANEIRO AU DÉBUT DU XXE SIÈCLE. Au moment où ont été réalisées des transformations urbaines considérables, l'image de "Paris des Tropiques" a été associée à Rio de Janeiro à et la ville a accueilli deux importants méga-événements: l' Exposition Nationale de 1908 et celle de 1922. Il s'est agi de stratégies urbaines promues par l'État, et les modernisations territoriales qui en ont découlé ont été très sélectives et exclusives, en accentuant la production des espaces occupés par les élites et la ségrégation socio-spatiale. Utilisés comme un prétexte pour l'expansion urbaine et la production et la conquête de terres urbaines, les méga-événements analysés ont induit une redéfinition de l'utilisation des sols et de leur répartition dans l'espace urbain, et ont donc eu une grande influence sur la structuration de la ville de Rio de Janeiro.

Mots clés: Méga-événements; géographie urbaine; production de l'espace urbain; structure urbaine; Exposition Nationale 1908; Exposition Internationale 1922.

\section{INTRODUÇÃO}

O Rio de Janeiro em breve sediará os Jogos Olímpicos de 2016 e esse acontecimento adquire grandes proporções na cidade, pois se trata do megaevento internacional de maior relevância (e repercussões espaciais) na atualidade para uma cidade: sediá-lo significa estar em evidência, em escala planetária. A cidade sediou ainda, no início do século XXI, megaeventos como os Jogos Pan-Americanos de 2007, o Rock in Rio (2011), o Rio +20 (2012), a Jornada Mundial da Juventude e a Copa das Confederações (ambos em 2013), e abrigou também parte da Copa do Mundo de 2014 no Brasil, tendo recebido consideráveis projetos de reestruturação urbana (como exemplo, intervenções na zona oeste da cidade, em área de expansão imobiliária na Barra da Tijuca, o atual projeto "Porto Maravilha", de requalificação e revitalização de sua área portuária, e os megaprojetos viários como a Transcarioca, Transolímpica e Transoeste). As intervenções espaciais na cidade em tempos de globalização, justificadas pela realização de megaeventos (e seus possíveis legados) e pela produção de uma imagem positiva da cidade, principalmente no que diz respeito a atração de capital, investimentos e turistas, implicaram em consideráveis impactos sociais, como podem ser constatados através dos inúmeros casos de remoção de população de baixa renda e das ações de pacificação de suas favelas que, por outro lado, estão atreladas a um processo de elitização do espaço, especulação imobiliária, criminalização e tentativas de se ocultar a pobreza e as contradições sociais aos olhos dos visitantes (La Barre, 2016). Nesse sentido, conforme o autor, é anunciada uma nova economia política: a economia política dos megaeventos, em detrimento da prioridade nas 
políticas sociais como as de saúde, educação e moradia. Apesar de parecer um fenômeno recente, dada a contemporaneidade do fato, o "olhar do mundo" para o Rio de Janeiro em função de um megaevento e suas repercussões socioespaciais têm sua origem num passado remoto, abrigado em um outro contexto histórico, social, político, econômico e cultural.

Naquele tempo (primeira e segunda década do século XX), tratava-se da promoção (ao próprio país e ao mundo) da recém-construída "Paris dos Trópicos", produzida aos moldes da reforma urbana de Paris na segunda metade do século XIX. Nesse contexto gesta-se o primeiro megaevento na cidade no Rio de Janeiro: a Exposição Nacional de 1908, realizada na então Capital Federal, em comemoração ao centenário da abertura dos portos brasileiros às nações amigas e assentada nos ideários de modernidade, civilidade e progresso. Alguns anos mais tarde, outro megaevento se realiza na área central da cidade: a Exposição Internacional de 1922, realizada em comemoração ao Centenário da Independência do Brasil e, basicamente, assentada sob os mesmos ideários da Exposição anterior.

É neste sentido que o tema central deste trabalho assenta no papel dos megaeventos no processo de produção do espaço urbano do Rio de Janeiro no início do século XX. Estes megaeventos ocorreram concomitantemente ao processo de europeização do espaço urbano carioca, através de mega-projetos urbanos cuja intencionalidade era a de se criar a "Paris dos Trópicos", moderna, em oposição à cidade colonial.

\section{MEGAEVENTOS E PRODUÇÃO DO ESPAÇO URBANO: QUESTÕES CONCEITUAIS}

Os megaeventos são verdadeiros espetáculos cujas expressões concretas são materializadas no espaço interno das cidades e se configuram, notadamente, como estratégias urbanas adotadas pelo poder público aliado à iniciativa privada, e trazem consigo uma profusão de mega-projetos urbanos (envolvendo construções diversas) que impactam diretamente na estrutura urbana das cidades, compreendida como o arranjo interno dos diferentes usos do solo num determinado momento (Sposito, 1991). A estrutura urbana é constantemente redefinida em função de diversos fatores, entre eles, a expansão territorial e os novos usos do solo que, no curso do processo de produção do espaço, e sob a ação de determinados agentes, implica na reestruturação da cidade. Diante do exposto, não há como desconsiderar o papel dos megaeventos no processo de produção do espaço urbano em seus diversos momentos e contextos. O espaço, compreendido como um resultado da inseparabilidade entre objetos e ações, entre materialidade e imaterialidade (Santos, 2002), possui natureza multifacetada e dinâmica: ao mesmo tempo em que é suporte das atividades humanas, é um produto social e histórico, em ininterrupto processo de produção através das ações do Estado, do Capital e da Sociedade.

Um evento tem com principais atributos, a grosso modo, a atração e congregação de pessoas, o caráter intrínseco da efemeridade, a relação com o lazer e o tempo livre, e a 
seletividade espaço-temporal na sua realização. Pode ser representado por exposições, feiras, festivais, espetáculos, congressos, encontros de caráter científico, cultural, comercial, social e/ou político, competições esportivas, etc., compreendendo, portanto, diversas naturezas, dimensões, escalas de alcance, duração e podendo também, por vezes, ocorrer de forma regular e com certa periodicidade.

Na visão de Seixas (2010: 6), megaeventos se traduzem em "eventos culturais ou desportivos de âmbito internacional ou mesmo planetário, ações coletivas e efêmeras que comportam status simbólicos e escalas espaciais e temporais muito significativas". O autor exemplifica sua análise referindo-se às Exposições Universais (ou as EXPOs, sua forma conhecida no presente), Copas do Mundo, Jogos Olímpicos e, em menor grau, Capitais da Cultura, Torneios de Tênis ou Grandes Regatas.

A estreita relação entre megaeventos e construção de edificado é amplamente discutida por Indovina (1999). O autor assevera que um megaevento só pode ser considerado como tal se produzir transformações urbanas (construções) no local onde se realiza, ou seja, o megaevento é considerado, também, como uma ocasião para a realização de obras relevantes na cidade, de forma a "enriquecê-la" ou mesmo tornar esses novos equipamentos urbanos úteis à coletividade, algo que nem sempre corresponde à realidade:

"A realização do "grande evento" produz edifícios que não podem ser utilizados senão dificilmente por funções diversas daquelas que foram projectadas e realizadas. Realizam-se, no âmbito do evento e segundo o seu conteúdo, obras "efêmeras" e obras "duradouras"; nem seria lógico, muitas vezes, realizar como duradouro aquilo que deveria ser efêmero. Uma determinada constante é individual pelo facto das obras públicas realizadas determinarem processos de valorização do rendimento, que alimentam processos especulativos e que perturbam o já complexo mercado de construção" (Indovina, 1999: 141).

Um megaevento refere-se, basicamente, à larga escala de abrangência, duração e visibilidade, à dimensão simbólica capaz de proporcionar a atração de pessoas e capitais e, sobretudo, à sua dimensão espacial, ou seja, ao seu poder de induzir, direta ou indiretamente, consideráveis transformações espaciais nas cidades nas quais os mesmos ocorrem. Essas transformações são manifestadas materialmente através da construção de edificado, obras de infra-estrutura, disponibilização ou conquista de novos terrenos (dotando-os de infra-estrutura e edificações diversas) e, por vezes, ocorre a ressignificação de áreas inteiras para a realização do megaevento, prevendo sua utilização futura, dado o seu caráter essencialmente efêmero (Molina, 2013).

No Rio de Janeiro, os megaeventos existentes no início do século XX se deram sob a lógica das Exposições Universais. As mesmas tiveram início num momento marcado, sobretudo, por um ideal de modernidade ligado à afirmação do modo de produção capitalista e da industrialização, e estavam imersas num contexto de grandes transformações sócio-espaciais impostas pela burguesia industrial em plena ascensão e à generalização do consumo e realização do capital na escala mundial. Esses espetáculos da modernidadei, sobretudo "manifestações de interesse econômico-produtivo" (Indovina, 1999: 135), permitiam que cada nação participante do evento demonstrasse, aos olhos de um 
grande público, as suas principais vicissitudes. Mais especificamente, as idéias de civilização, desenvolvimento, progresso e modernidade tinham que estar expostas no recinto das Exposições. Esses megaeventos podem ser considerados "auto-representações populares da burguesia industrial" (Plum, 1979: 6). Neles eram expostos produtos diversificados, máquinas, processos industriais de produção (e assim uma imagem de tecnificação progressiva), inovações científicas e tecnológicas, novos produtos e mercadorias, assim como novos valores, hábitos e comportamentos intrinsecamente ligados à ideologia da sociedade industrial.

As Exposições apresentavam, por tais fins, um caráter pedagógico, propagandístico e ideológico, num ambiente onde era visível a competitividade entre as nações participantes, cada qual expondo seus êxitos, progressos, modernidades. Conforme Canogar (1992), o recinto das Exposições tinha efeito hipnótico no público, através do aspecto visual dos edifícios, das cores, formas, estrutura interna, vitrines, máquinas em movimento e sons: a experiência do visitante era, acima de tudo, sensorial. Ao mesmo tempo, ocultavam-se as pressões físicas e psicológicas vividas pelos trabalhadores nas fábricas, junto às mesmas máquinas exibidas na Exposição. Outra característica dessas exposições era a coexistência entre a diferenciação, competição e integração ou, em outras palavras, entre elementos de identidade nacional, geopolíticos e de relações internacionais.

A imagem de uma sociedade industrial sem conflitos fazia-se presente nas Exposições Universais. Expunham-se as máquinas, as técnicas de produção e as mercadorias, mas a representação do mundo laboral presente no processo produtivo existente no interior da indústria, da exploração da força de trabalho e a realidade cotidiana do trabalhador ficava fora de cogitação. Ali, a classe operária era somente consumidora e expectadora dos produtos de sua força de trabalho e de um modelo de sociedade que se impunha, num momento que antecedeu o consumo massivo de produtos industriais.

As contradições inerentes às relações entre países desenvolvidos e em vias de desenvolvimento estavam também presentes nas Exposições Universais. O chamado Velho Continente valorizava nessas exposições seus países mais industrializados, desenvolvidos, de prosperidade econômica, civilizados, ao mesmo tempo em que as nações ditas do terceiro mundo (e das então colônias) expunham, basicamente, matérias-primas, técnicas agrícolas e aspectos embrionários de uma industrialização tardia. Conforme Plum (1979: 140), havia também casos de países não-europeus cuja "performance" fora bem sucedida durante a participação na Exposição Universal de 1851 em Londres (a primeira realizada), como os Estados Unidos, Canadá e Austrália, sendo os dois últimos, na época, ainda colônias.

O nacionalismo fazia-se presente no contexto "universal" das Exposições, e isso se refletia também nas datas em que esses megaeventos eram realizados. Podemos citar, como exemplos, a Exposição de Filadélfia (1876), realizada por ocasião do centenário da independência dos Estados Unidos, e a Exposição de Paris (1889), em comemoração aos cem anos da Revolução Francesa. No caso brasileiro, como será explorado mais adiante, a Exposição Nacional de 1908 e a Exposição Internacional de 1922 também celebram centenários de datas importantes no contexto nacional, como a Abertura dos Portos às Nações Amigas (1808) e a Independência do Brasil (1822). 
A primeira Exposição Universal, intitulada The Great Exhibition of the Works of Industry of all Nations, teve duração aproximada de cinco meses em Londres (01 de maio a 11 de outubro de 1851), e recebeu um total de 6039195 pessoas, cuja média diária era de 43000 visitantes. Esta Exposição foi idealizada fundamentalmente para mostrar ao mundo a superioridade industrial britânica na época (Pesavento, 1997), e foi realizada no Hyde Park com a construção do Palácio de Cristal, uma gigantesca estrutura pré-fabricada transparente (de ferro, vidro e madeira) que abrigava o recinto da Exposição. Além de ser revolucionário do ponto de vista arquitetônico, seu espaço interno era racionalmente organizado por diversas e largas "avenidas" interligando os muitos salões que abrigavam as diferentes nações e as diversidades existentes no planeta. Anos mais tarde, o Barão Haussmann transformava Paris praticamente do dia para a noite, construindo largos boulevards que ordenavam espacialmente a cidade e, nesse sentido, Canogar (1992: 29) afirma que "la Gran Exposición de Londres fue un laboratório experimental de la ciudad racionalista del futuro, presagiando el tipo de cambios que iban a modificar el paisaje urbano de las principales capitales europeas".

As Exposições Universais estimularam também interesses privados, uma vez que atraíam grande número de empresários e técnicos de diversos países a participar do então maior e principal meio publicitário da indústria. Ter seus produtos premiados nessas Exposições era garantia de projeção internacional e ganho econômico. Por atrairem grande número de visitantes e induzir o deslocamento espacial de pessoas, essas exposições impulsionaram a prática de viagens mediada por um mercado ainda incipiente:

\footnotetext{
“Thomas Cook (1808-1892), que desde 1841 havia atuado como agente de viagens junto às Estradas de Ferro Inglesas, fez-se conhecer em 1851, entre a população do centro e do norte da Inglaterra, em particular entre a classe operária, através de viagens de trem a preços módicos, à Exposição de Londres. 3\% do total dos que visitaram a Exposição Mundial, fizeram-no por intermédio da agência de viagens de Cook" (Plum, 1979: 88).
}

Há que se considerar, portanto, que a primeira Exposição Universal coincidiu com as primeiras viagens organizadas, inaugurando uma forma então embrionária do que hoje se conhece por turismo de massa e excursionismo.

Após a Grande Exibição de Londres em 1851, sucessivas Exposições Universais ocorreram e merecem destaque por sua expressão, sobretudo, geográfica, tendo em vista profundas transformações urbanas no espaço interno das cidades que as sediaram. A Exposição realizada em Paris no ano de 1867 (época de Napoleão III) ocorreu às margens do Rio Sena, no Campo de Marte, e teve como edifício central o colossal Palais du Champs de Mars ou Palácio Elíptico, de forma oval e aspecto labiríntico em seu interior. Ao redor do Palácio Elíptico existiam outras construções representando os diversos países participantes, os chamados pavilhões. Nesse sentido, os pavilhões internacionais (construídos com arquitetura típica dos países que representavam, de forma por vezes pitoresca, traduzindo-se num verdadeiro ecletismo arquitetônico) têm sua gênese em 1867 e a partir de então tornam-se um modelo a ser seguido nas futuras Exposições, inclusive aquelas sediadas no Rio de Janeiro, como será detalhado mais adiante. Os pavilhões eram, em si, 
objetos de contemplação e ganhavam, por vezes, mais atenção do que o próprio edifício central da Exposição, como foi o caso do Palácio do Campo de Marte, cujas pretensões educativas despertavam menos interesse dos visitantes perante a diversidade do parque existente do lado de fora, contemplando a diversidade dos países e exibindo o exótico (Pesavento, 1997; Molina, 2013).

No ano de 1878, Paris sediou outra Exposição Universal, ocupando novamente o Campo de Marte e se estendendo à outra margem do Rio Sena, na colina do Trocadero, onde foi construído o Palácio do Trocadero. Nessa última, concentravam-se os pavilhões dos países e, junto aos mesmos, construiu-se, pela primeira vez numa Exposição Universal, a Rua das Nações, cujos moldes foram reproduzidos em exposições seguintes, não só na França (Canogar, 1992). Conforme o autor, na terceira Exposição realizada em Paris, em 1889, o espetáculo ganhou proporções superiores às precedentes no Campo de Marte e no Trocadero. Neste caso, além das duas áreas antes mencionadas, foram utilizadas, também, a Esplanade des Invalides e o Quai d'Orsay. O grande feito dessa Exposição talvez tenha sido a Torre Eiffel, construída exclusivamente para o megaevento com o fim de ser, além de um ícone urbano de forte poder de atração de pessoas, um objeto visando proporcionar ao público uma visão panorâmica da exposição e da própria cidade de Paris (na época, a maior obra arquitetônica existente no mundo).

Esse fato representa um marco no que diz respeito à construção de uma obra monumental de grande apelo lúdico e o exemplo seguido ocorre na Exposição Universal de Chicago (1893), com a construção de uma roda gigante de ampla visão panorâmica, utilizada posteriormente na Exposição de Saint Louis em 1904. A Exposição de Chicago foi a maior existente até aquele momento e inaugurou explicitamente os investimentos e esforços no aspecto lúdico dos visitantes com a criação de parque de diversões, projeções cinematográficas, teatros, espetáculos pirotécnicos e iluminação noturna dos edifícios e fontes. Desde então, o apelo ao entretenimento passa a marcar também as Exposições, tornadas, a partir daí, espaços de lazer cuja produção objetivava atrair mais pessoas (Pesavento, 1997). Construída às margens do Lago Michigan, numa zona pantanosa ao sul da cidade e relativamente distante da área central, a Exposição de Chicago marcou também o uso de um megaevento como pretexto à conquista de terrenos até então desocupados e desprovidos de infra-estrutura urbana (portanto, espaços improdutivos). Ali foram construídos canais, lagunas e um amplo sistema de transporte tanto para se chegar na exposição quanto no seu espaço interno, representando ações centradas na dinamização dos fluxos e movimento das pessoas (Plum, 1979; Canogar, 1992).

O espetáculo proporcionado pela eletricidade e pelas luzes é superado por Paris na Exposição Universal de 1900, que continha até mesmo um Palácio da Eletricidade e inaugurava, ainda, os chamados Chateau d'Eau, imensas fontes iluminadas localizadas na frente dos principais edificios. A Exposição Universal de Paris de 1900 apresenta suma importância no que tange à produção do espaço urbano parisiense, uma vez que parte das novas construções tornaram-se elementos estruturantes de sua paisagem urbana e impulsionou, ainda, o aprimoramento da mobilidade na cidade, como explicitado por Pesavento (1997: 222): 


\begin{abstract}
"Paris se renovara com algumas novas construções, como o Grand Palais, o Petit Palais e a Ponte Alexandre III, obras que deveriam sobreviver à exposição, e se aparelhara com o novo transporte metropolitano subterrâneo, solução moderna para os transportes urbanos das grandes metrópoles".
\end{abstract}

Como citado anteriormente, os megaeventos tornam-se, em determinado momento, pretextos para a conquista e integração de novas áreas ao tecido urbano das metrópoles que os sediam, sendo inclusive impulsionadores de requalificação urbana em determinados lugares do espaço intra-urbano, acompanhados, por vezes, da produção de ícones urbanos. Isso pode ser exemplificado também por Barcelona, cidade que, ao longo da história, sediou duas Exposições Universais (1888 e 1929). Com a Exposição de 1888 construiu-se o Arco do Triunfo, o Parque da Cidadela, o Monumento a Colón e a urbanização de parte da frente marítima; na Exposição de 1929, consideráveis transformações urbanas ocorreram em uma área junto ao monte Montjuic, além da recuperação do centro histórico da cidade.

No decorrer do século XX, as Exposições Universais vão perdendo seu grau de importância, cedendo lugar a megaeventos esportivos internacionais impulsionadores, no contexto da globalização e da competitividade dos lugares, de consideráveis transformações urbanas. Com o desenvolvimento dos meios de transporte e comunicação, megaeventos esportivos são mais fortemente tomados como ferramentas de desenvolvimento econômico, social e urbano (Hall, 2006). No Rio de Janeiro, os megaeventos sediados nas duas primeiras décadas do século passado inserem-se na mesma lógica existente nas Exposições Universais europeias e, nesse contexto, serão apresentadas e analisadas a seguir as repercussões dos mesmos no espaço intra-urbano carioca.

\title{
III. O RIO DE JANEIRO NO INÍCIO DO SÉCULO XX
}

Fundada em 01 de março de 1565, sendo capital do país durante 197 anos (1763 até 1960), a cidade do Rio de Janeiro, até o início do século XX, foi marcada pela presença de moradias precárias, ruas sujas, estreitas e mal iluminadas, repleta de habitações coletivas (representadas pelos cortiços), e com graves problemas relacionados à salubridade, como a constante presença de pestilências, entre elas, febre amarela, malária, peste bubônica, beribéri e varíola.

A vinda da Família Real (1808), a Independência do Brasil (1822) e o reinado do café foram elementos que configuraram o dinamismo político, social e econômico na cidade que, até 1870 , possuía uma população representada, basicamente, por escravos, trabalhadores livres de baixa renda, imigrantes (sobretudo comerciantes portugueses), uma aristocracia dirigente e fazendeiros do café. A separação e segregação espacial dos habitantes "só foi possível, entretanto, devido à introdução do bonde de burro e do trem a vapor que, a partir de 1870, constituíram-se de grandes impulsionadores do crescimento físico da cidade" (Abreu, 2010: 36-37), marcando dessa forma os primórdios da expansão urbana do Rio de Janeiro. 
Desde finais do século XIX, sucessivas modernizações vêm se impondo ao seu território, ao mesmo tempo em que novas contradições sócio-espaciais afloram e se intensificam no curso da história. No espaço interno da metrópole, os investimentos (vetores de modernização territorial) dirigiram-se, em grande parte, inicialmente para o Centro (onde se encontra também a área portuária), estendendo-se rumo à Zona Sul, conhecida como o "cartão-postal" da cidade, onde se localizam os bairros de Botafogo, Urca, Copacabana, Ipanema, Leblon, entre outros.

Ainda no final do século XIX presencia-se, no Rio de Janeiro, uma industrialização incipiente nas proximidades da área central, sendo transferida para os subúrbios no século seguinte ${ }^{\mathrm{ii}}$. Segundo Abreu (2010: 54), as indústrias, nesta época, eram pouco mecanizadas e marcadas, principalmente, pela fabricação de calçados, chapéus, confecções, bebidas, mobiliários e têxteis (estas últimas se instalaram desde o início nos subúrbios, como Bangú, Piedade, Baixada Fluminense e também em Laranjeiras e proximidades do Jardim Botânico $)^{\mathrm{iii}}$.

É efetivamente a partir do início do século XX que houve, no Rio de Janeiro, uma sucessão de planos urbanísticos visando primordialmente o "embelezamento da cidade", segundo um modelo europeu inspirado no Barão Haussmann, responsável pela reforma urbana de Paris na segunda metade do século XIX e tendo como marco inicial a Reforma Passos, em 1902. No intuito de tornar o Rio de Janeiro a "Paris dos Trópicos", eliminando os traços da cidade colonial, Pereira Passos buscou, em sua gestão (1902-1906), transformar o Rio de Janeiro em uma cidade moderna e, através de um discurso higienista, deu início a uma série de obras de grande impacto no espaço urbano da então capital do Brasil.

\section{A “REFORMA PASSOS” E A PRODUÇÃO DA “PARIS DOS TRÓPICOS”}

As intervenções urbanas na área central do Rio de Janeiro ocorreram em uma operação conhecida como "Bota-Abaixo", realizada pelo então prefeito, o engenheiro Francisco Pereira Passos. Além de demolições de grande parte da área central (desapropriação de inúmeros prédios e arrasamento de cortiços), construção de jardins, alargamento de ruas e construção de avenidas no centro e na orla (figs. 1 e 2), a Reforma Passos atuou na reestruturação do sistema viário da cidade em sua totalidade, partindo das áreas centrais; houve a construção de túneis sob morros e a otimização dos meios de transporte, facilitando o acesso a áreas mais distantes nas Zonas Norte e Oeste e também possibilitando o acesso para áreas à beira-mar na Zona Sul.

Neste sentido, o Estado, cedendo a pressões da burguesia urbana carioca, dispende grandes quantias de recursos para contornar as barreiras naturais em direção à Zona Sul, para viabilizar interesses da classe alta em ocupar esta parcela da cidade, marcada pela presença da orla marítima como um atrativo natural, representando um importante fator de expansão urbana e atração da população de alta renda.

Dentre as obras mais significativas da operação "Bota Abaixo", destacam-se o arrasamento do Morro do Senado (próximo à área portuária), a construção da Avenida Beira Mar e da Avenida Central, ambas inauguradas em 1905. A Avenida Beira Mar represen- 
tou a melhoria da acessibilidade da zona sul (Botafogo) ao centro do Rio de Janeiro, sendo a Avenida Central (atual Rio Branco) marcada pela instalação de edifícios imponentes como o Teatro Municipal, a Biblioteca Nacional, a Escola de Belas Artes, o Supremo Tribunal Federal e o Palácio Monroe.

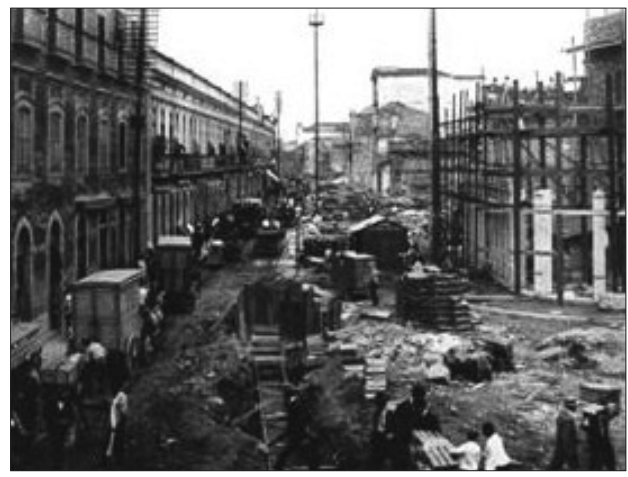

Fig. 1 - Obras na Rua da Carioca (1905).

Fig. 1 - Works in the Street of Carioca (1905).

Fonte: Ermakoff, 2009: 52 (Foto: Augusto Malta, 1905)

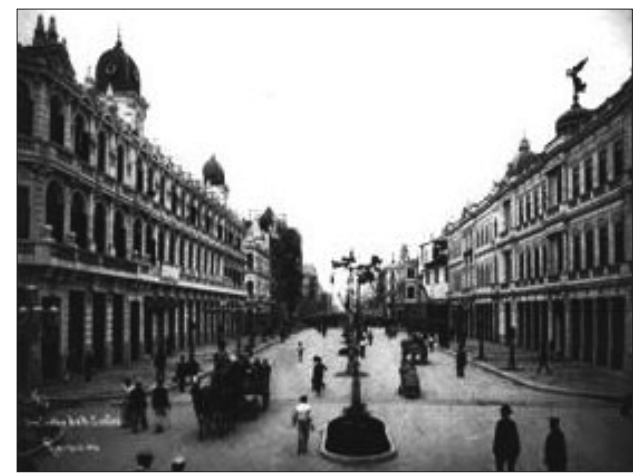

Fig. 2 - Avenida Central (1906).

Fig. 2 - Central Avenue (1906).

Fonte: Ermakoff, 2009: 55. (Foto: Augusto Malta, 1906)

A operação "Bota-Abaixo" de Pereira Passos pode ser considerada um marco, na história do Rio de Janeiro, da atuação hegemônica do Estado na produção do espaço urbano carioca, ampliando as condições da reprodução do capital na cidade já no início do século XX. Estas ações envolveram, também, a expropriação da população pobre habitante dos cortiços nas áreas centrais, liquidando-se o "feio", de modo a garantir-se o "belo" nos moldes europeus. A cidade do Rio de Janeiro torna-se, assim, uma espécie de "Paris dos Trópicos" (expressão cunhada e difundida pela imprensa local, nessa época), substituindo formas antigas que serviam de entrave à ideia de modernização que se pretendia à época.

A importância da Reforma Passos, segundo Abreu (2010: 63), reside basicamente em três aspectos: a) representou o primeiro exemplo da intervenção do Estado na produção do espaço urbano carioca determinado sob a lógica excludente da eliminação da população de baixa renda na área central (e mais valorizada) da cidade; b) impôs transformações urbanas pautadas na eliminação de formas pretéritas mediante a determinação de novas funções à cidade e c) representou um exemplo de como novas contradições são geradas a partir de tentativas de resolução de outras: ao eliminar os cortiços, uma população pobre, que necessitava residir próximo ao local de trabalho, passou a ocupar os morros e encostas na área central, dando origem às favelas que, a partir desse momento, começam a se proliferar pela cidade.

É no contexto da "Paris dos Trópicos" e da almejada modernidade no Rio de Janeiro ligada aos padrões europeus e, mais especificamente, franceses, que se realizam a Exposição Nacional de 1908 e a Exposição Internacional de 1922, ambas concebidas aos moldes das Exposições Universais, "espetáculos da modernidade" que vinham se concretizando na Europa desde a segunda metade do século XIX. 


\section{AS GRANDES EXPOSIÇÕES E A PRODUÇÃO DO ESPAÇO URBANO NO RIO DE JANEIRO}

No Rio de Janeiro, a Exposição Nacional de 1908 e a Exposição Internacional de 1922, ambas concebidas aos moldes das Exposições Universais, tiveram um forte conteúdo simbólico e envolveram, além de novas construções (boa parte delas, efêmeras), a conquista/produção de solo urbano na cidade, como veremos nas linhas seguintes.

\section{Exposição Nacional de 1908}

Concebida em comemoração ao centenário da abertura dos portos brasileiros às nações amigas, a Exposição Nacional de 1908 foi organizada pelo governo federal, pelos estados brasileiros participantes, pelas associações comerciais, agrícolas e industriais (Fabian \& Rohde, 2007). O intuito maior era o de mostrar ao país e ao mundo um Rio de Janeiro moderno (agora sem grandes resquícios da cidade colonial) em função das reformas da cidade e sua europeização e, ao mesmo tempo, um Brasil republicano, em progresso e civilizado. Portanto, as idéias de civilidade, progresso e modernidade, almejadas pela jovem nação republicana, marcaram a Exposição Nacional de 1908 no Rio de Janeiro.

A realização da Exposição Nacional de 1908 contou com a criação de um espaço para abrigar diversos pavilhões monumentais, cada um representando os estados brasileiros (fig. 4), exceto um pavilhão, o português (fig. 3). A convite do Presidente Afonso Pena, Portugal foi o único país participante da Exposição de 1908 e teve, assim, o seu próprio pavilhão, cedido pelo governo brasileiro (Pesavento, 1997).

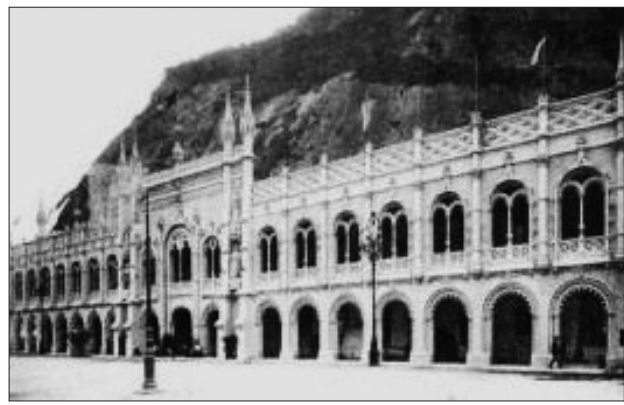

Fig. 3 - Pavilhão Português.

Fig. 3 - Portuguese Pavilion.

Fonte: Boletim Comemorativo da Exposição Nacional de 1908 (1908: 32)

(Foto: Augusto Malta, 1905)

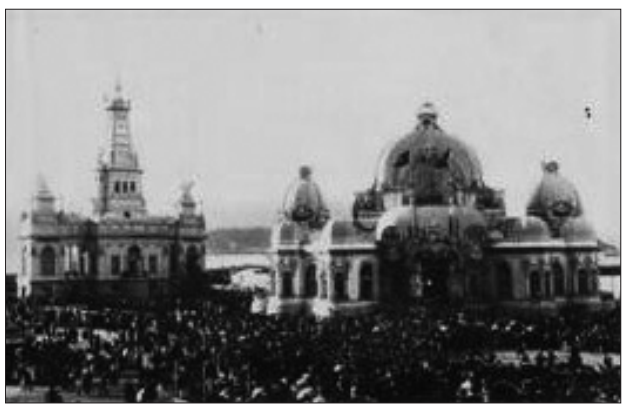

Fig. 4 - Pavilhão dos Estados de Minas Gerais (esq.) e São Paulo (dir.).

Fig. 4 - Pavilion of the States of Minas Gerais (left) and São Paulo (right).

Fonte: Acervo do Museu da Imagem e do Som/RJ (Foto: Augusto Malta, 1908)

A Exposição teve duração de três meses (de 11 de agosto a 15 de novembro de 1908) e foi organizada em quatro seções: Agricultura, Indústria Pastoril, Indústrias e Artes Liberais (Rio de Janeiro, Directoria Geral de Estatística, 1908). O espaço utilizado loca- 
liza-se no bairro da Urca, abrangendo desde a antiga Praia da Saudade e seu cais (que atualmente corresponde à Avenida Pasteur e dependências do Iate Clube), até a Praia Vermelha, em terreno situado entre os morros da Babilônia e da Urca, ocupando uma área de $182000 \mathrm{~m}^{2}$ (figs. 5, 6 e 7).

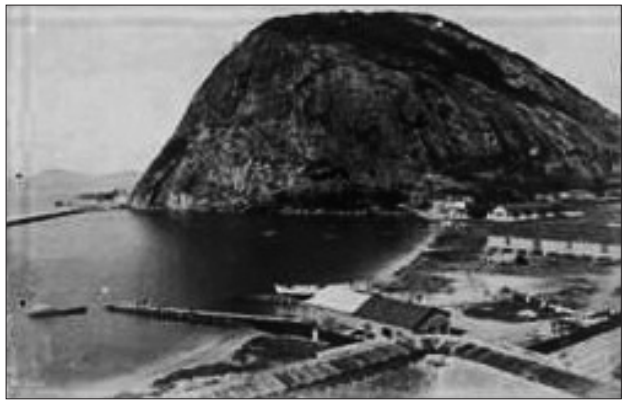

Fig. 5 - Vista do Morro da Urca e da Praia da Saudade.

Fig. 5 - View of the Hill of Urca and Saudade Beach.

Fonte: Acervo do Museu da Imagem e do Som/RJ (Foto: Augusto Malta, 1907)

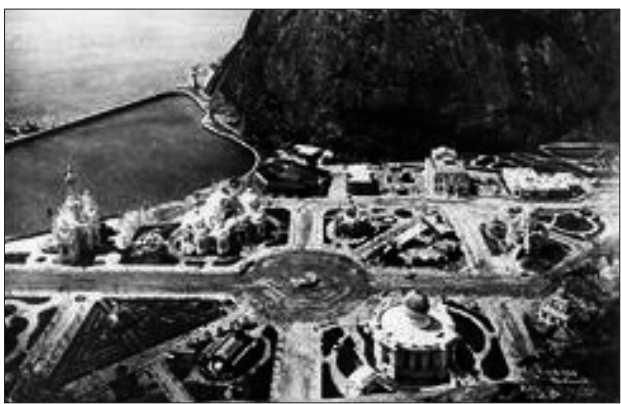

Fig. 6 - Vista Panorâmica da Exposição Nacional de 1908.

Fig. 6 - Panoramic View of 1908

National Exhibition.

Fonte: Museu da República (disponível em http://www.republicaonline.org.br)

(Foto: Augusto Malta, 1908)

Apesar de ter sido idealizada e organizada juntamente com agentes privados, foi o Estado o grande investidor na montagem da exposição e nas transformações implementadas no bairro da Urca (Levy, 2008). A ocupação inicial da Urca foi marcada pela defesa da baía de Guanabara e materializada por fortificação, igreja e pequenas casas de madeira e taipa, e assim permaneceu, basicamente, até o início do século XX, quando o bairro é integrado à malha urbana do Rio de Janeiro, impulsionado pela realização, nessa área, da Exposição Nacional de 1908.

Para a Exposição, além dos pavilhões dos estados brasileiros e de Portugal, foram construídas avenidas, ruas, praças, e um pequeno trem na área interna (que percorria toda a exposição). O local contava também com a instalação da Estação (de bondes) da Companhia Ferro-Carril Jardim Botânico ${ }^{\text {iv }}$ e da Estação Marítima, situada no molhe da Urca, essa última proporcionando o deslocamento de pessoas através de barcas, saindo do cais Pharoux, no centro da cidadev. Essas infra-estruturas de acesso impulsionaram a dinamização (e expansão) da mobilidade urbana e dos fluxos, numa área até então "distante" da área central, praticamente inabitada e fundamentalmente de uso militar, e que, a partir do recebimento de investimentos em função da realização da Exposição, ganha nova expressão na cidade, adquire novo uso e é ressignificada. 


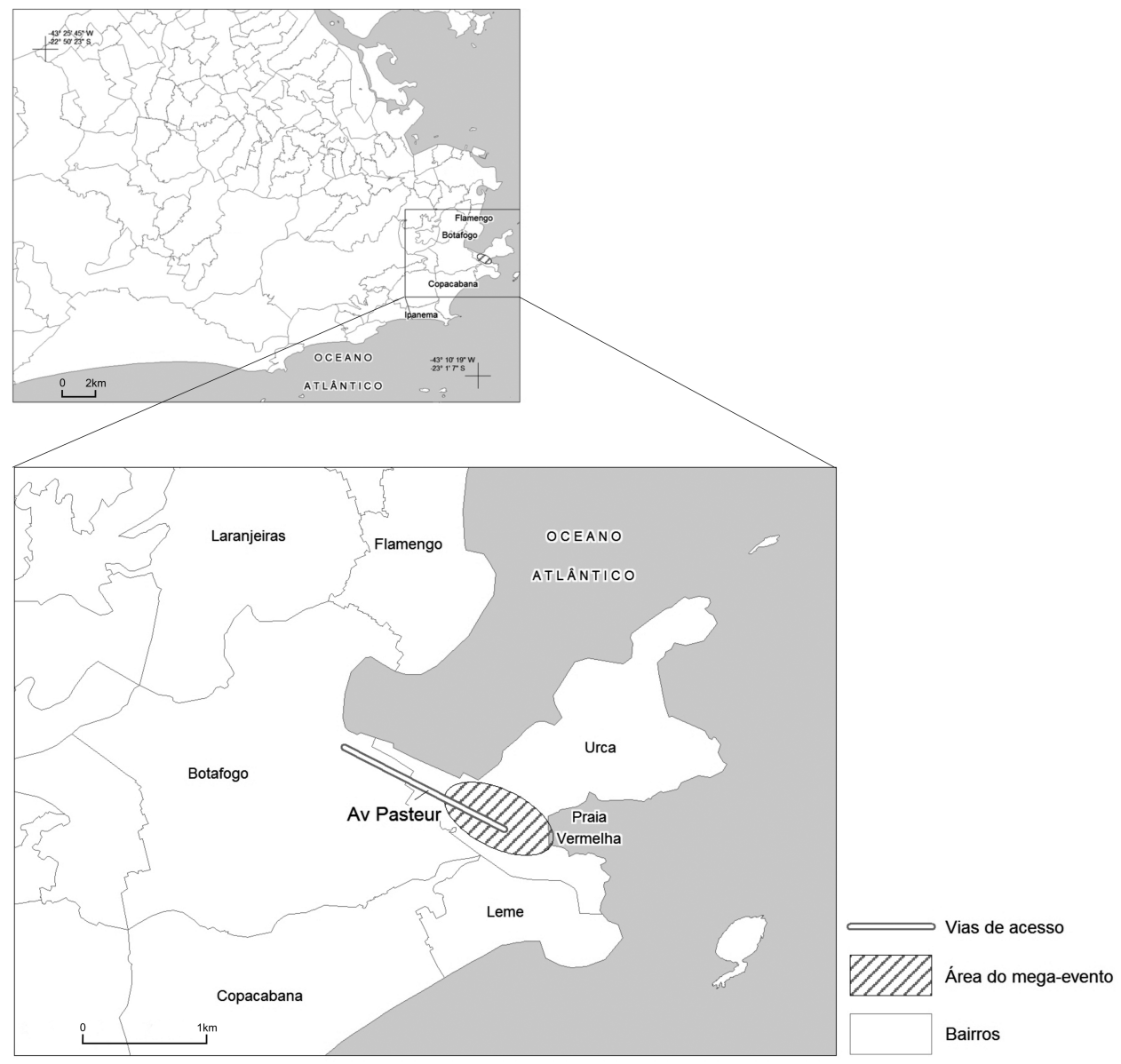

Fig. 7 - Localização da Exposição Nacional de 1908.

Fig. 7 - Location of the 1908 National Exhibition. Fonte: Base Cartográfica do IBGE (2010). Elaboração: Mónica R. A. Garcia

Praticamente a totalidade dos pavilhões construídos no recinto da Exposição apresentava estrutura frágil, normalmente de madeira coberta com estuque, representando um exemplo de arquitectura efêmera e, por sua beleza e imponência, configuravam-se como parte dos objetos da exposição. Alguns poucos edifícios pré-existentes foram utilizados, como o prédio da Escola Militar ${ }^{\mathrm{vi}}$, que foi adaptado para abrigar o Pavilhão das Indústrias (fig. 8), e o edifício do Pavilhão dos Estados (fig. 9) que teve o início de sua construção em 1881, inicialmente para abrigar a primeira universidade brasileira. $\mathrm{O}$ Pavilhão dos Estados era o prédio principal da Exposição e o mesmo não tinha o caráter de "arquitetura efêmera", como a grande maioria dos outros pavilhões existentes: era o maior deles, com $7600 \mathrm{~m}^{2}$ e 91 salas para abrigar a exposição dos Estados que não possuíam um pavilhão próprio. 


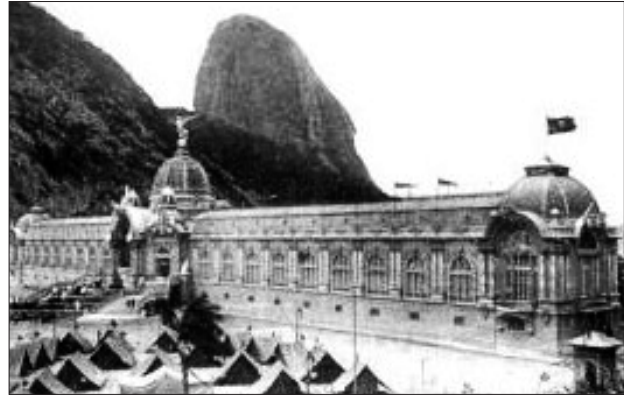

Fig. 8 - Pavilhão das Indústrias.

Fig. 8 - Pavilion of Industries.

Fonte: Boletim Comemorativo da Exposição

Nacional de 1908 (1908)

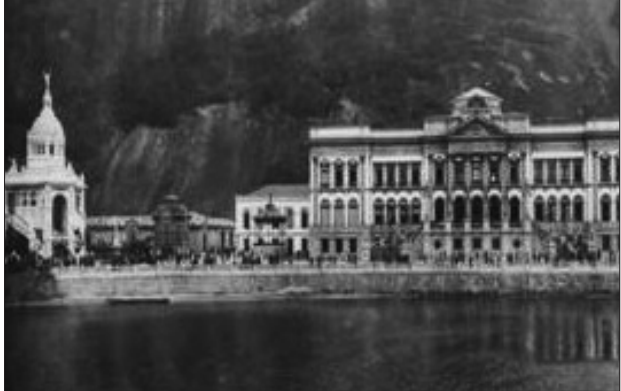

Fig. 9 - Pavilhão dos Estados

e Porta Monumental.

Fig. 9 - Pavilion of the States

and Monumental Gate.

Fonte: Acervo do Museu da Imagem e do Som/RJ

(Foto: Augusto Malta, 1908)

Atividades culturais e artísticas eram constantes no espaço da Exposição e funcionavam como mais uma estratégia de captação de público e, assim, o aspecto lúdico concorria com o apelo didático. Durante os três meses em que permaneceu ativa, dezenas de estrangeiros (autoridades, jornalistas) foram convidados para fins de divulgação do megaevento assim como da cidade e do país no exterior, e a Exposição Nacional de 1908 "recebeu mais de um milhão de visitantes. Um número considerável para um país que tinha cerca de 22 milhões de habitantes" (Fabian \& Rohde, 2007: 5).

Da necessidade, neste momento, de aprimorar os meios de hospedagem na cidade, criou-se o decreto 1 160, em 23 de dezembro de 1907 (Prefeito Sousa Aguiar), referente à isenção de impostos, durante sete anos, aos "cinco primeiros hotéis que se instalassem na cidade do Rio de Janeiro. Essa medida foi pioneira e constitui um divisor de águas entre o período de implantação da hotelaria na cidade e sua expansão em busca da modernidade" (Machado, 2005: 73). Neste contexto é inaugurado, em 1908, o Hotel Avenida, um marco da hotelaria na cidade, uma vez que, a partir de então, a cidade contaria com instalações hoteleiras modernas em contraposição às precárias hospedarias existentes.

A essa multidão foi exibido, na remodelada e moderna capital federal, um Brasil exuberante, moderno, sem antigos traços coloniais, e sob a idéia de progresso e desenvolvimento tecnológico e industrial, fato presente nas Exposições Universais antes comentadas. O Governo Federal solicitou a intelectuais e escritores renomados da época (como Euclides da Cunha, João do Rio e Olavo Bilac, este último, contratado como jornalista oficial da Exposição) para o acompanhamento e exaltação da Exposição por meio da imprensa. Os meios de comunicação, portanto, apresentavam-se como ferramenta importante no evento e também na formação da opinião pública sobre o próprio país, num contexto em que pairava, "por cima de tudo, a exacerbação de um país que ainda se queria constituir como nação - e para tanto usava a feira para fins políticos, exaltando o nacionalismo (eternamente) em formação" (Scherer, 2011: 6). 
Por fim, o bairro da Urca é efetivamente integrado na cidade e urbanizado na década de 1920, sob a gestão do prefeito Carlos Sampaio, inserido num período marcado por grandes obras públicas na região central e na zona sul da cidade. Carlos Sampaio foi, inclusive, responsável pelo desmonte do Morro do Castelo, criação de aterro e obras diversas para a Exposição do Centenário da Independência em 1922. Nesse mesmo ano foi aprovado o plano geral de arruamento e loteamento da Urca e construído o Hotel Balneário, junto à praia, e situado no ponto mais central do bairro. A valorização do solo à beira mar é inerente ao surgimento do bairro da Urca, e essa tendência se propaga em outros bairros da Zona Sul, aos poucos ocupados pelas classes mais abastadas.

\section{Exposição Internacional de 1922}

Em plena área central da cidade do Rio de Janeiro situava-se o Morro do Castelo (junto à Avenida Rio Branco ${ }^{\text {vii }}$ e próximo à orla marítima), lugar habitado por população pobre, que vivia em cortiços e em péssimas condições de salubridade. O então prefeito Carlos Sampaio promoveu seu desmonte, que acarretou na remoção dessa população da área central do Rio de Janeiro, sob um discurso higienista e em nome da estética. A administração de Carlos Sampaio denota, também, o papel do poder público na valorização de terrenos que a Prefeitura captava para si, através de melhorias urbanísticas e obras de saneamento, no intuito de atrair empreendimentos imobiliários.

Essa área foi utilizada para abrigar a Exposição Internacional do Centenário da Independência do Brasil, de 1922, na cidade do Rio de Janeiro, que objetivava celebrar as comemorações do centenário da independência do país. Assim, uma área destinada a sediá-lo deveria ser preparada: a escolha do centro e, mais especificamente, o local onde se encontrava o Morro do Castelo, foi estratégica. A Exposição Internacional de 1922 foi mais uma justificativa para o seu desmonte (fig. 10), cujo material foi ainda utilizado para aterro das Praias de Santa Luzia (fig. 11) e da Lapa; com isso, um grande espaço $\left(384424 \mathrm{~m}^{2}\right)$ foi conquistado na região central, representado pelo "vazio" proporcionado pelo desmonte do Morro (uma área que, por estar próxima à Avenida Rio Branco, era considerada a de maior valorização do solo da cidade) e pelo avanço sob o mar, na forma de aterro. Conforme Martins (1998: 126-127), os principais argumentos utilizados para justificar o desmonte do Morro foram: a) sua presença impedia arejar a cidade, pois o mesmo atuava como uma barreira física contra os ventos; b) seu ambiente era insalubre e ocupado por população "sem importância" e força política; c) sua localização central era excepcional, com excelente possibilidade de negócios futuros; d) seu desmonte proporcionaria altos lucros à Prefeitura, basicamente através da venda de terrenos ou negociações com grupos capitalistas em troca de serviços, e ainda através da possibilidade de ganhos pelos impostos gerados pelas novas áreas, contribuindo assim no aumento da arrecadação municipal. 


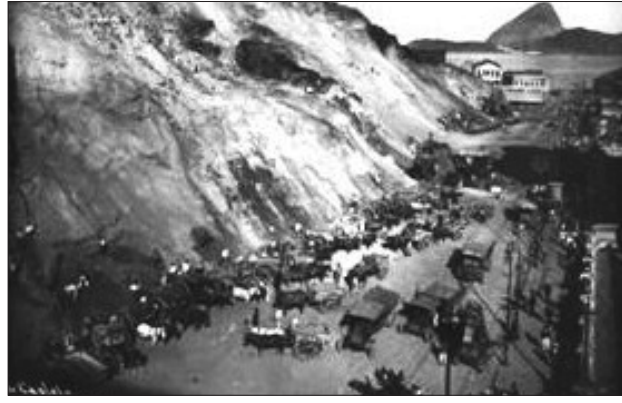

Fig. 10 - Desmonte do Morro do Castelo.

Fig. 10 - Dismount of the Hill of the Castle.

Fonte: Ermakoff, 2009: 143

(Foto: Augusto Malta, 1921)

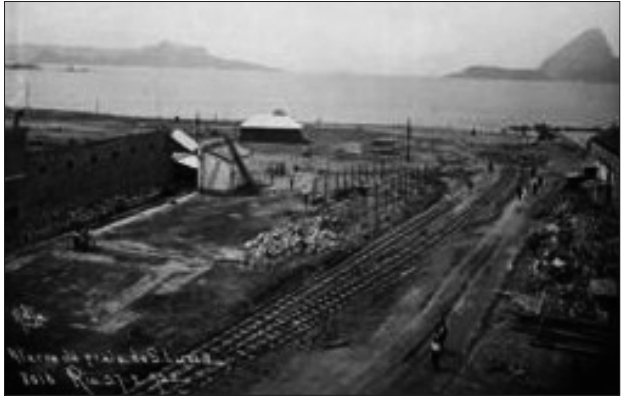

Fig. 11 - Aterro da Praia de Santa Luzia e, ao fundo, o Pão de Açúcar.

Fig. 11 - Embankment of the Santa Luzia Beach and Sugar Loaf in the background. Fonte: Acervo do Museu da Imagem e do Som/RJ (Foto: Augusto Malta, 1921)

As obras foram iniciadas em 1920 e, além de sofrer atrasos consideráveis (o que implicou na aceleração das mesmas às vésperas da Exposição), foram criticadas pela imprensa da época pelos gastos vultuosos, que incluíam, além da derrubada do Morro do Castelo e aterro, o calçamento de ruas e o embelezamento da área, visando adequá-la às comemorações do Centenário e à necessária construção dos pavilhões dos países participantes.

Localizada em pleno centro da cidade (fig. 12), a Exposição Internacional do Centenário da Independência do Brasil ocupava uma extensão de aproximadamente 2500 metros, desde o Passeio Público, junto ao Palácio Monroe viii, até o Mercado Municipal, ambos utilizados na Exposição. Na Praça Mauá havia também um anexo da Exposição, e ali se instalaram, fundamentalmente, as estruturas para expor a produção industrial dos países participantes (exceto Portugal, que teve o Pavilhão das Indústrias localizado na Avenida das Nações). Ao todo, 16 seções (subdivididas em grupos e classes) compreendiam a Exposição: 1) Agricultura, 2) Indústria Pastoril, 3) Várias Indústrias, 4) Comércio, 5) Economia Geral, 6) Economia Social, 7) Estatística, 8) Ensino, 9) Transportes e Vias de Comunicação, 10) Serviços Públicos, 11) História e Geografia, 12) Imprensa, 13) Esportes, 14) Arte Militar, 15) Belas Artes, 16) Higiene/Assistência (Levy, 2010: 129).

A Exposição mostrou-se, portanto, como justificativa às intervenções realizadas na cidade do Rio de Janeiro na área escolhida para abrigá-la. Da mesma forma, caracterizava-se também pelo poder de atração de um grande contingente de visitantes, nacionais e estrangeiros, fazendo com que o turismo impulsionado por esse megaevento de caráter internacional servisse, ainda, como um pretexto às ações do Estado no que tange às intervenções urbanas e à construção da imagem tanto da cidade do Rio de Janeiro perante o país como do próprio país perante o mundo. Todo o trabalho de divulgação nacional e internacional da Exposição (especialmente a partir dos Consulados do Brasil no exterior) foi realizado durante os seus preparativos e esse megaevento contribuiu para projetar, mundialmente, a "nova" imagem da cidade do Rio de Janeiro, inclusive, por meio de cartões postais. 


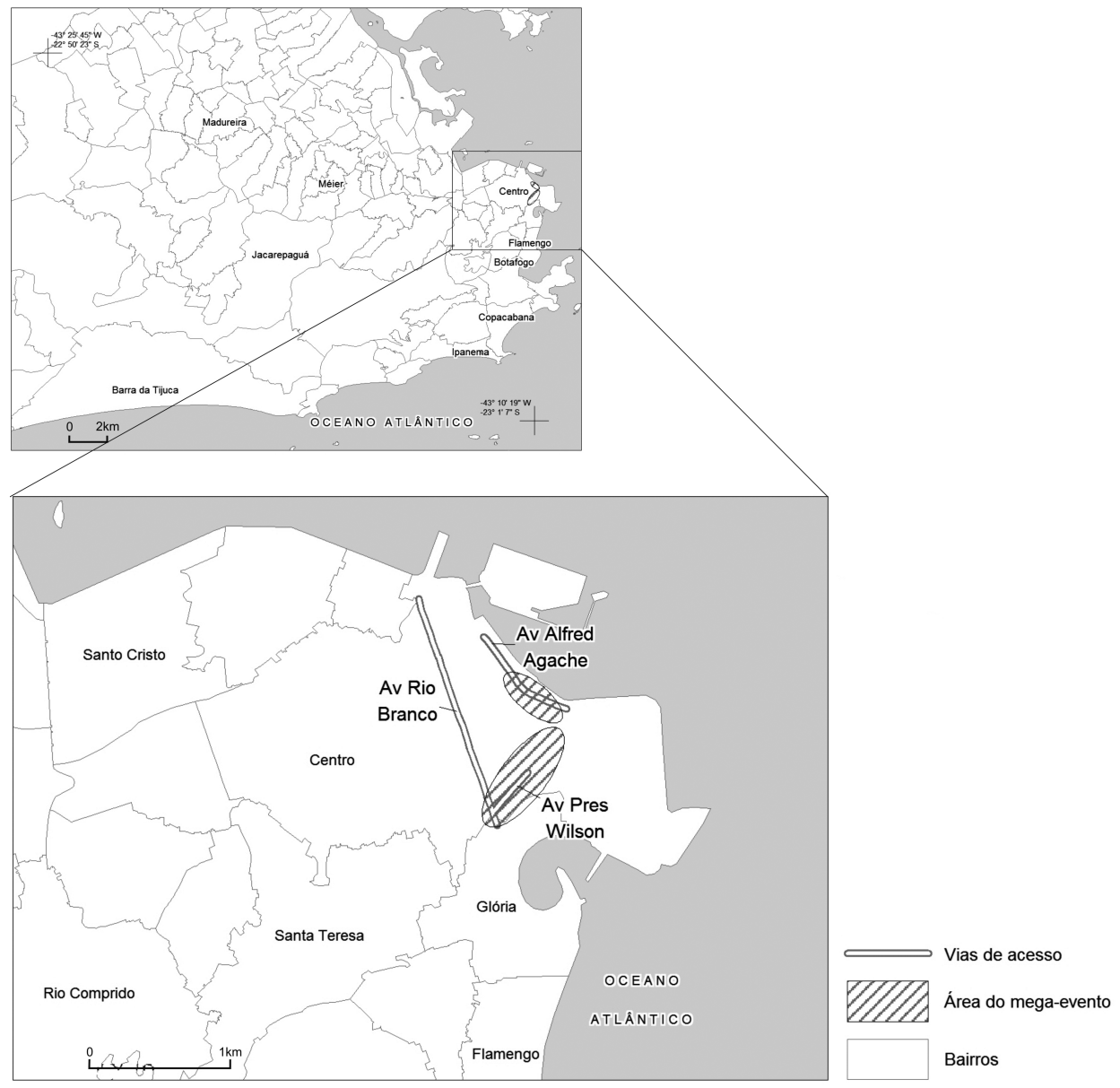

Fig. 12 - Localização da Exposição Internacional de 1922.

Fig. 12 - Location of the 1922 International Exhibition.

Fonte: Base Cartográfica do IBGE (2010). Elaboração: Mónica R. A. Garcia

Com o incremento do turismo na cidade, ligado diretamente ao evento, o Presidente Epitácio Pessoa incentivou a construção de hotéis no Rio de Janeiro, tendo em vista a quantidade e qualidade insuficientes da hotelaria na cidade para acomodar os turistas brasileiros e estrangeiros. Antes da Exposição alguns hotéis já existiam, como o Hotel Palace, no centro, e o Hotel Balneário, na Urca, mas três hotéis em específico foram encomendados por Epitácio Pessoa para a Exposição, sendo esses o Hotel Glória (na época o maior e mais luxuoso da América do Sul, inaugurado em setembro de 1922, tendo sido o único a ficar pronto até a data de inauguração da Exposição), Hotel Copacabana Palace (que, devido aos atrasos em sua construção, foi inaugurado somente no fim da Exposição) e Hotel Sete de Setembro, conhecido também como Hotel do Centenário (inaugurado em 15 de julho de 1922). 
Inaugurada em 07 de setembro de 1922, a Exposição Internacional de 1922 no Rio de Janeiro durou até 24 de julho de 1923, em sessão solene de encerramento realizada no Palácio das Festas. Recebeu, desde a inauguração até o dia 02 de julho de 1923, um total de 3626402 visitantes, sendo 12723 a média diária de visitação (Levy, 2010: 143). O recinto da Exposição contava com diversos edifícios como palácios, pavilhões (figs. 14, 15 e 16), quiosques, bares, restaurantes e cinema, e o ambiente era também caracterizado pelo aspecto lúdico, incluindo um parque de diversões (fig. 13), espetáculos pirotécnicos, concertos, festas, bailes e solenidades (o recinto da Exposição contava com um total de 80 construções).

Ao todo, 13 países participaram da Exposição: Argentina, Estados Unidos, Japão, França, Inglaterra, Itália, Dinamarca, México, Tchecoslováquia, Noruega, Bélgica, Portugal e Suécia. Apresentava, assim, uma parte internacional, situada basicamente na Avenida das Nações (atual Avenida Presidente Wilson), e outra parte nacional, situada na outra extremidade da Exposição e, basicamente, junto à área onde se encontrava o antigo Mercado Municipal.

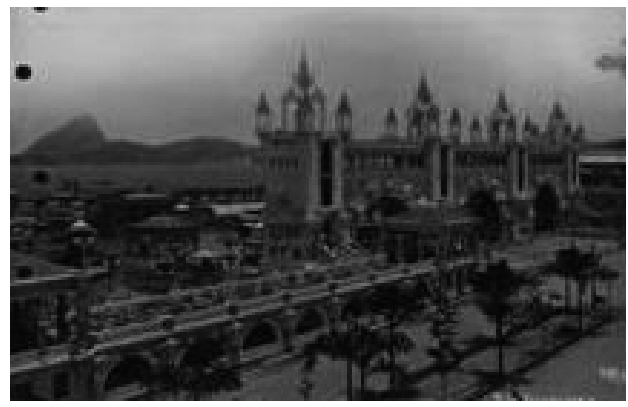

Fig. 13 - Parque de diversões da Exposição Internacional de 1922.

Fig.13 - Amusement Park of the 1922

International Exhibition.

Fonte: Acervo do Museu da Imagem e do Som/RJ (Foto: Augusto Malta, 1922)

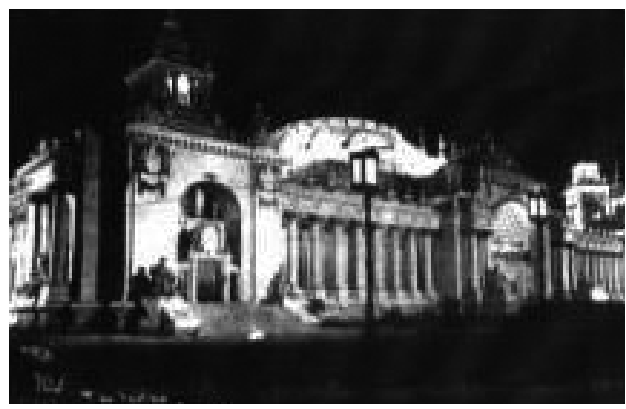

Fig. 15 - Palácio das Festas.

Fig. 15 - Palace of Events. Fonte: Acervo do Museu da Imagem e do Som/RJ (Foto: LEVI, 2010: 180)

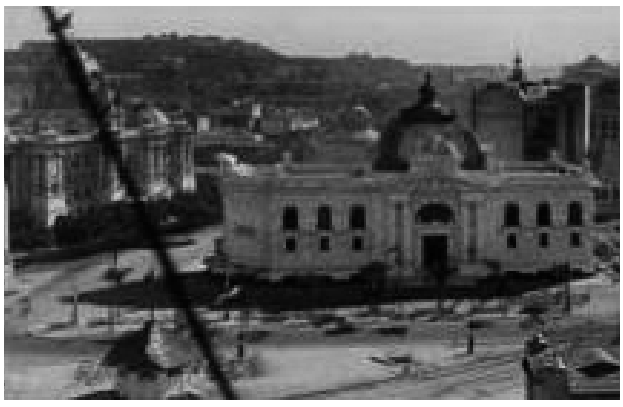

Fig. 14 - Pavilhão da Argentina.

Fig. 14 - Pavilion of Argentina. Fonte: Acervo do Museu da Imagem e do Som/RJ (Foto: Augusto Malta, 1922)

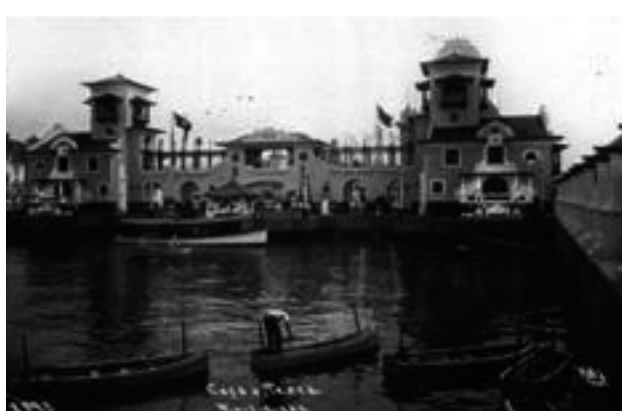

Fig. 16 - Pavilhão da Caça e da Pesca.

Fig. 16 - Pavilion of the Hunting and Fishing. Fonte: Acervo do Museu da Imagem e do Som/RJ (Foto: Ermakoff, 2009: 152) 
Assim como ocorreu em 1908, grande parte das construções em 1922 tinha um caráter efêmero e daí sua demolição após a Exposição, salvo algumas exceções, como o Pavilhão dos Estados Unidos, que foi destinado à sede da embaixada americana no Brasil, e o Pavilhão da França (cópia do Petit Trianon, de Versailles), que abriga, até hoje, a Academia Brasileira de Letras. Dos pavilhões nacionais, o Pavilhão dos Estados Brasileiros (um dos maiores da exposição, com cinco pavimentos) foi construído com o intuito de ser edificação definitiva e após a Exposição abrigou a Secretaria de Estado de Agricultura, Indústria e Comércio, e a edificação do Pavilhão das Grandes Indústrias encontra-se adaptada e ocupada atualmente pelo Museu Histórico Nacional. O Pavilhão do Distrito Federal também foi preservado e nos dias de hoje abriga a sede do Museu da Imagem e do Som.

Em suma, a Exposição Internacional de 1922 conformou-se como um significativo pretexto e justificativa às intervenções em plena área central do Rio de Janeiro, sobretudo a conquista de terrenos em decorrência do desmonte do Morro do Castelo e dos aterros. Eliminou-se um resíduo do passado que se configurava como um obstáculo às ações hegemônicas e à difusão do novo: o Morro do Castelo era, assim, uma barreira espacial, representada por sua dimensão tanto material quanto simbólica, uma vez que era visto como um símbolo representativo dos vestígios coloniais inerentes a um passado que se queria apagar com as ações de modernização do espaço urbano carioca.

\section{CONSIDERAÇÕES FINAIS}

Este artigo buscou compreender o papel dos megaeventos na produção do espaço urbano do Rio de Janeiro no início do século XX, época a qual a cidade foi produzida como a "Paris dos Trópicos", eliminando-se os traços coloniais existentes que representavam um retrocesso às ideias de modernidade, civilidade e progresso, que tanto se pretendia na jovem nação republicana.

Através da Exposição Nacional de 1908 e da Exposição Internacional de 1922, o poder público utilizou destes megaeventos enquanto estratégias urbanas: as modernizações territoriais se mostraram altamente seletivas e excludentes, através da introdução de novos conteúdos materiais e imateriais que se realizaram ligados à ideologia e à política, concretizando-se na própria produção de lugares elitizados e destinados a cumprirem certas funções determinadas por intencionalidades hegemônicas. Inovações introduzidas em função da realização destes megaeventos no Rio de Janeiro se concentraram nas áreas potencialmente valorizáveis (como é o caso do Bairro da Urca) e nas já valorizadas como a própria área central da cidade, utilizando-se de padrões de urbanização importados, especificamente aqueles inspirados na reforma urbana de Paris pelo Barão Haussmann. Essa reforma urbana, da década de 1860, era pautada num ordenamento espacial visando o embelezamento e a eliminação dos traços medievais de Paris (sob um discurso higienista), basicamente através de desapropriações, demolições, construção de largas avenidas e abertura de boulevares. No Rio de Janeiro, esse modelo foi aplicado em con- 
traposição à cidade colonial e industrial pré-existente, com a eliminação de cortiços e, como exemplo maior, a construção da Avenida Beira Mar e a abertura da Avenida Central (atual Avenida Rio Branco).

Após a Exposição Nacional de 1908, o bairro da Urca inseriu-se no movimento de integração de terrenos à cidade e de valorização seletiva de parcelas do solo urbano carioca, especialmente aquelas à beira-mar e rumo à Zona Sul, em um contexto inerente a fragmentos espaciais comercializados pelo mercado imobiliário, tendo o Estado como aliado e provedor de infra-estrutura urbana.

No centro do Rio de Janeiro, na ocasião da Exposição Internacional de 1922, a população de baixa renda ali existente foi inicialmente expulsa com a Reforma Passos, sendo novamente submetida ao mesmo processo na gestão de Carlos Sampaio, nas obras para a Exposição. A esses habitantes, restou "ocupar o subúrbio, longe do mercado de trabalho e mal servido de infra-estrutura e transportes, ou as favelas junto ao centro" (Martins, 1998: 125), numa situação oposta à presenciada na zona sul da cidade, dotada de infra-estrutura, transporte de bondes e ocupada por classes mais abastadas. A Exposição Internacional de 1922 deu-se em um momento de emergência de uma elite industrial no país, que perdia seu caráter essencialmente agrário e, portanto, a imagem de um Brasil industrial é almejada no ensejo da Exposição e, ao mesmo tempo, buscava-se difundir, em território nacional, o estilo de vida europeu, "moderno" e civilizado (como ocorreu também no momento da Exposição Nacional de 1908). Conforme Corrêa (1989), o centro do Rio de Janeiro é caracterizado, na segunda metade do século XX, pelo uso intensivo do solo e ampla concentração vertical, pelos elevados preços da terra, pela alta concentração diurna, sendo ainda foco de transportes intra-urbanos e área de decisões. Assim, a urbanização e o desenvolvimento de boa parte do núcleo central (CBD) do Rio de Janeiro a partir de terrenos conquistados e justificados em nome da Exposição Internacional de 1922 reforçaram o grau de centralidade do centro do Rio de Janeiro.

Utilizados como pretexto da expansão urbana (conquista de terrenos e sua integração à malha urbana), da produção de solo urbano e do reforço de centralidade na própria área central do Rio de Janeiro, os megaeventos analisados induziram redefinições dos usos do solo e de seu arranjo no espaço interno da cidade, mostrando-se relevantes, portanto, na estruturação urbana da cidade do Rio de Janeiro no início do século XX.

\section{REFERÊNCIAS BIBLIOGRÁFICAS}

Abreu, M. (2010). Evolução Urbana do Rio de Janeiro. (4.ed.). Rio de Janeiro: Instituto Pereira Passos.

Canogar, D. (1992). Ciudades efímeras: Exposiciones Universales: espectáculo y tecnología. Madrid: Anjana Ediciones.

Corrêa, R. (1989). O espaço urbano. São Paulo: Editora Ática.
Ermakoff, G. (2009). Augusto Malta e o Rio de Janeiro 1903-1936. (2. ed.). Rio de Janeiro: G. Ermakoff Casa Editorial.

Fabian, A. \& Rohde, B. (2007). Progresso e modernidade: sonho de uma nação. Revista Eclética, 25, 2-6.

Hall, C. (2006). Urban entrepreneurship, corporate interests and sports mega-events: the thin policies of 
competitiveness within the hard outcomes of neoliberalism. In Horne, J. \& Manzenreiter, W. (Eds.), Sports mega-events: social scientific analyses of a global phenomenon (pp. 59-69). Oxford: Blackwell.

Indovina, F. (1999). Os grandes eventos e a cidade ocasional. In Ferreira, V. \& Indovina, F. (Orgs.), A cidade da EXPO'98: uma reconversão na frente ribeirinha de Lisboa? (pp. 126-143). Lisboa: Editorial Bizâncio.

La Barre, J. (2016). Future shock: mega-events in Rio de Janeiro. Leisure Studies, 35(3), 352-368.

Lessa, C. (2005). O Rio de todos os Brasis: uma reflexão em busca de auto-estima. (3. ed.). Rio de Janeiro: Editora Record.

Levy, R. (2010). A exposição do centenário e o meio arquitetônico carioca no início dos anos 1920. Rio de Janeiro: Editora EBA/UFRJ.

Levy, R. (2008). Entre palácios e pavilhões: a arquitetura efêmera da Exposição Nacional de 1908. Rio de Janeiro: Editora EBA/UFRJ.

Machado, M. (2005). A formação do espaço turístico do Rio de Janeiro. In Bartholo, R., Delamaro, M. \& Badin, L. (Orgs.), Turismo e sustentabilidade no Rio de Janeiro. (pp. 44-80). Rio de Janeiro: Garamond.

Martins, A. (1998). A Exposição Internacional de 1922 no Rio de Janeiro: um espaço urbano turístico na jovem república brasileira. In Rio, V. del (Org.),
Arquitetura: pesquisa e projeto. (pp. 121-146). Rio de Janeiro: FAU UFRJ.

Molina, F. (2013). Mega-eventos e produção do espaço urbano no Rio de Janeiro: da "Paris dos Trópicos" à "Cidade Olímpica". (Dissertação de doutoramento). São Paulo: Universidade de São Paulo.

Pesavento, S. (1997). Exposições Universais: espetáculos da modernidade do Século XIX. São Paulo: HUCITEC.

Plum, W. (1979). Exposições Mundiais no século XIX: espetáculos da transformação sócio-cultural. Bonn: Friedrich-Ebert-Stiftung.

Rio de Janeiro, Directoria Geral de Estatística (1908). Boletim Commemorativo da Exposição Nacional de 1908. Rio de Janeiro: Typographia da Estatística.

Santos, M. (2002). A natureza do espaço: técnica e tempo, razão e emoção. São Paulo: EDUSP.

Scherer, M. (2011). Cem anos de imprensa em exibição: jornais e jornalistas na Exposição Nacional de 1908. In I Congresso Mundial de Comunicação Ibero-Americana - Confibercom. São Paulo: Anais do Congresso (ECA/USP).

Seixas, J. (2010). Os mega-eventos na cidade: imagem social, política econômica e governança urbana. E-metropolis, 2 (1), 4-9.

Sposito, M. (1991). O centro e as formas de expressão da centralidade urbana. Revista de Geografia, 10, 1-18.

i Expressão utilizada por Pesavento (1997).

ii É este o momento em que o bairro de São Cristóvão (situado na zona norte do Rio de Janeiro e próximo à área central) sofre significativas transformações: deixa de ser o bairro que abrigava a família real para agora atrair indústrias (que tinham interesse pela localização próxima aos eixos ferroviários, ao porto e ao centro) e também a "difusão da ideologia que associava o estilo de vida "moderno" à localização residencial à beira mar" (Abreu, op. cit.,: 47), implicando no deslocamento das classes mais abastadas rumo à zona sul.

iii A multiplicação de indústrias, assim como o declínio da atividade cafeeira, também são fatos importantes que ocorreram no final do século XIX, assim como o adensamento populacional na cidade em função das indústrias. Essas, com o incentivo do Estado, constroem vilas operárias e casas populares nas áreas abertas pelas ferrovias, levando Abreu (2010: 57) a afirmar que "trem, subúrbio e população de baixa renda passavam a ser sinônimos aos quais se contrapunha a associação bonde/zona sul/estilo de vida "moderno'”'

iv Que desde 1900 detinha a concessão das linhas de bonde para a Zona Sul, extinta em 1952.

v Onde atualmente se encontra a Estação das Barcas, na Praça XV de Novembro, com partidas para a Ilha de Paquetá, Ilha do Governador e Niterói.

vi Esse edificio, inaugurado em 1864 junto à Praia Vermelha, situava-se em frete à praia, bloqueando a vista para o mar.

vii Em 1912 a Avenida Central passa a se chamar Avenida Rio Branco.

viii O Palácio Monroe foi uma estrutura utilizada no pavilhão do Brasil na Exposição de 1904 em Saint Louis (EUA), e ali ganhou medalha de ouro no Prêmio Mundial de Arquitetura. Ao final de Exposição de Saint Louis, a construção foi desmontada e trazida ao Brasil, sendo reerguida em 1906 no Rio de Janeiro e utilizada na Exposição de 1922 como Escritório da Exposição e Bureau de Informações. Após o evento, o Palácio Monroe abrigou a sede da Câmara dos Deputados Federais e, ao fim da década de 1970, foi demolido em função das obras do metrô na cidade do Rio de Janeiro. 